\title{
Metformin Reduces Oxidative Stress Status and Improves Plasma Insulin Level in Streptozotocin-Induced Diabetic Rats
}

\author{
Umar Zayyanu Usman, Ainul Bahiyah Abu Bakar and Mahaneem Mohamed \\ Department of Physiology, School of Medical Sciences, Universiti Sains Malaysia, 16150 Kubang Kerian, \\ Kelantan, Malaysia
}

\begin{abstract}
Background: Oxidative stress induced by hyperglycaemia plays a crucial role in the development of diabetic complications and metformin is commonly used in treating diabetes mellitus (DM). The aim of this study was to investigate whether metformin at the dose of $100 \mathrm{mg} / \mathrm{kg} /$ day could ameliorate oxidative stress and improve plasma insulin level in streptozotocin-induced diabetic rats.

Methods: Twenty one rats (8-10 week old; weighing 190-220 g) were assigned into three groups ( $\mathrm{n}=7$ rats per group) i.e. non-DM, DM and DM+metformin (100 mg/kg/day metformin) groups. DM was induced using streptozotocin $(60 \mathrm{mg} / \mathrm{kg})$ intraperitoneally and treatments were given daily by oral gavage for four weeks. The levels of plasma biomarkers such as fasting blood glucose, oxidant-antioxidant markers and insulin levels were analysed.

Results: Fasting blood glucose, malonyldehyde and protein carbonyls levels were significantly higher while insulin, total antioxidant capacity, catalase and glutathione peroxidase levels were significantly lower in DM group compared to nonDM group. The levels of fasting blood glucose, malonyldehyde and protein carbonyls were significantly lower while levels of total antioxidant capacity, catalase and insulin were significantly higher in DM+metformin group compared to DM group.

Conclusion: This study may suggest that metformin at the dose of $100 \mathrm{mg} / \mathrm{kg} /$ day for 4 weeks reduces oxidative stress status and improves plasma insulin level in streptozotocin-induced diabetic rats possibly through its antihyperglycaemic action.
\end{abstract}

Keywords: Oxidative stress, rats, diabetes, metformin, insulin.

\section{INTRODUCTION}

Diabetes mellitus (DM) is a metabolic disease characterized with hyperglycaemia, resulting from defects in insulin secretion, action or both [1]. Gradually it alters normal body metabolism and is reported to significantly reduce important nutrient in the body leading to higher mortality rate associated with DM [2]. Metformin has been the main therapy in DM for many centuries and its inhibition on hepatic gluconeogenesis, anti-glucagon action and insulin sensitising action help in DM management [3]. Moreover, metformin also decreases intestinal glucose absorption and increases peripheral glucose utilization [4]. It belongs to the class of biguanide drug to lower blood glucose level without causing hypoglycaemia [5].

Hyperglycaemia promotes auto-oxidation of glucose to form free radicals and, part of the oxygen taken into the body may produce reactive oxygen species (ROS) and radicals. ROS are toxic in the body and selectively affect specific oxidant-sensitive proteins and tissue in the body [6]. Beta cells of pancreas are sensitive to ROS because they have low antioxidant enzymes [7].

*Address correspondence to this author at the Department of Physiology, School of Medical Sciences, Universiti Sains Malaysia, 16150 Kubang Kerian, Kelantan, Malaysia; Tel: +6097676158; Fax: +6097653371;

E-mail:mahaneem@usm.my
Administration of metformin at the dose of 50 $\mathrm{mg} / \mathrm{kg} / \mathrm{day}$ for 2 weeks significantly reduces blood glucose, improves insulin and reduces malonyldehyde (MDA) levels in fructose fed rat's model of type 2 DM [8]. Another study shows that metformin at the dose of $25 \mathrm{mg} / \mathrm{kg} /$ day for 2 weeks significantly improves antioxidant enzymes [superoxide dismutase (SOD), catalase (CAT) and glutathione reductase] and reduces MDA level in alloxan-induced type 1 diabetic model, with no concomitant measurement of blood glucose and insulin levels [9]. Although, both alloxan and streptozotocin are diabetogenic chemicals, the half-life of alloxan is shorter, and it acts through redox reaction and autoxidation of dialuric acid destroying the whole islet of Langerhans. On the other hand, streptozotocin has longer half-life with alkylating potency, which acts by targeting mitochondrial DNA, specifically leading to beta cells impairment and damage [10].

However, to date, no study has been reported on oxidative stress status with concomitant measurement of insulin and blood glucose levels in animal model using streptozotocin that is commonly used as the diabetogenic agent, treated with metformin at the dose of $100 \mathrm{mg} / \mathrm{kg} / \mathrm{day}$ that is corresponding to the human dose, and at the duration of more than 2 weeks. Therefore, the aim of this study was to investigate the (c) 2016 Lifescience Global 
effects of metformin at the dose of $100 \mathrm{mg} / \mathrm{kg} /$ day for 4 weeks on oxidative stress status, plasma insulin and blood glucose levels in streptozotocin-induced diabetic rats.

\section{MATERIAL AND METHODS}

\subsection{Experimental Animals}

Twenty one female Sprague Dawley rats weighing between $190-220 \mathrm{~g}$, aged 8-10 week were purchased from the animal house of the Universiti Sains Malaysia, Health Campus, Kelantan, Malaysia. Animals were housed for a period of one week to acclimatise in a standard cage at $25 \pm 2{ }^{\circ} \mathrm{C}$, with 12 hour light/dark cycle. They were maintained with food and water ad libitum. The study was approved and performed in accordance with the guidelines by the Animals Ethical Committee, Universiti Sains Malaysia (USM/Animal Ethics Approval/2013/90/503).

\subsection{Chemicals}

Streptozotocin was purchased from Sigma Aldrich Company Ltd., Dorset, UK, and digital glucometer was purchased from Muenster (Accu-Chek, Roche Diagnostic, Mannheim, Germany). Commercial kits for the assays of total protein and plasma antioxidants enzymes [Total Protein, SOD, CAT and glutathione peroxide (GPx) EnzyChrom ${ }^{\mathrm{TM}}$ assay kits, Bioassay Systems, California, USA)] and, oxidative stress markers [total antioxidant capacity (TAC) (Total Antioxidant Power assay kit, Oxford Biomedical Research, Michigan, USA); MDA (MDA assay kit, Northwest Life Sciences Specialist, Washington, USA and protein carbonyl (PCO) (PCO Colorimetric Assay kit; Cayman Chemical, Michigan, USA)] and plasma insulin kit (Rat insulin assay kit, Cloud-Clone Corp., Texas, USA) were purchased. All other reagents used for the study were of analytical grade.

\subsection{Induction of Diabetes}

Experimental diabetes mellitus was achieved by intraperitoneal injection of streptozotocin as a single dose of $60 \mathrm{mg} / \mathrm{kg}$ body weight in normal saline, to rats after fasting for 16 hours [10]. The normal control group received similar volume of saline buffer intraperitoneally only as vehicle. After 48 hours of injections, the fasting blood glucose (FBG) was measured using digital glucometer monitoring system based on glucose oxidase principle [11]. Animals that had blood glucose level of $\geq 200 \mathrm{mg} / \mathrm{dl}$ were considered diabetes.

\subsection{Experimental Design}

Twenty one female rats were randomly assigned into three groups ( $n=7$ rats per group) i.e. non-DM: as a negative control group (on $0.5 \mathrm{ml} /$ day of distilled water), DM: as a positive control group (DM on 0.5 $\mathrm{ml} /$ day of distilled water) and DM+metformin: as a treatment group (DM on $100 \mathrm{mg} / \mathrm{kg} /$ day of metformin). The treatments were given daily by oral gavage for 4 weeks. Blood glucose was estimated on the first day as initial FBG (week 0) and final FBG after the treatments (week 4) were recorded. After the last day of treatments, all the animals were fasted overnight and anaesthetized using $80 \mathrm{mg} / \mathrm{kg}$ ketamine and $5 \mathrm{mg} / \mathrm{kg}$ xylaxine. Blood sample was taken through cardiac puncture and analysed for FBG, antioxidants enzymes (CAT, SOD and GPX), oxidative stress markers (TAC, MDA and PCO) and plasma insulin levels.

\subsection{Analysis of Oxidant-Antioxidant Markers}

SOD activity was estimated using EnzyChrom ${ }^{\text {TM }}$ SOD assay kit. In this assay, superoxide was provided by xanthine oxidase catalysed reaction. The superoxide reacted with a WST-1 dye to form a coloured change. SOD in the sample scavenged the superoxide thus less superoxide was available for the chromogenic reaction. The colour intensity measured at $440 \mathrm{~nm}$ wavelength was used to determine the SOD activity from the standard curve and expressed as $\mathrm{U} / \mathrm{mg}$ protein [12].

CAT activity was estimated using EnzyChrom ${ }^{\mathrm{TM}}$ CAT assay kit. This assay directly measured catalase degradation of hydrogen peroxide using redox dye. The change in colour intensity at $570 \mathrm{~nm}$ was directly proportional to the catalase activity in the sample which was expressed as $\mathrm{U} / \mathrm{mg}$ protein [13].

GPx activity was estimated using EnzyChrom ${ }^{\mathrm{TM}}$ GPx assay kit. In this assay, NADPH consumption in the enzyme coupled reactions was directly measured. The measured decrease in optical density at $340 \mathrm{~nm}$ was directly proportional to the enzyme activity in the sample which was expressed as $\mathrm{U} / \mathrm{mg}$ protein [14].

TAC was estimated Total Antioxidant Power assay kit in which the reaction of reduced $\mathrm{Fe}^{+3}$ to $\mathrm{Fe}^{+2}$ was chelated by 2,4,6-tri (2pyridyl)-s-triazine and formed the complex $\mathrm{Fe}^{+2}-\mathrm{TPTZ}$. This complex showed an intense blue colour read at $450 \mathrm{~nm}$ which was directly proportional to the TAC in the sample. The level of TAC was calculated from the standard curve and expressed as $\mathrm{nmol} / \mathrm{mg}$ protein [15]. 
MDA was estimated using MDA assay kit based on the reaction of MDA with thiobarbituric acid (TBA) forming an MDA-TBA2 adduct which was read at $514 \mathrm{~nm}$. MDA level was calculated from the standard curve and expressed as nmol/mg protein [16].

PCO was measured PCO Colorimetric Assay kit. In this assay, 2,4-dinitrophenylhydrazine reacted with PCO to produce protein-hydrozone which was read at $370 \mathrm{~nm}$. The level of PCO was calculated from the controls and expressed as $\mathrm{nmol} / \mathrm{mg}$ protein [17].

Total protein concentration was estimated using Total Protein Assay kit based on an improved Coomassie blue $G$ method. The dye formed a blue complex specifically with protein and the intensity of colour was measured at $595 \mathrm{~nm}$. The colour change was directly proportional to the total protein concentration in the samples and expressed as $\mathrm{mg} / \mathrm{mL}$ protein and used for the expression of oxidantantioxidant markers [18].

\section{STATISTICAL ANALYSIS}

Data obtained were analysed using InStat 3.1 (Charlesworth Group Ltd, Huddersfield, UK). Result are expressed as mean and standard deviation, and analysed for statistical significance using one-way analysis of variance (ANOVA) followed by TukeyKramer post-hoc test. The $p<0.05$ was considered statistically significant.

\section{RESULTS}

\subsection{Fasting Blood Glucose Levels}

The mean FBG level of non-DM group was almost invariable throughout the experimental study. On the contrary, FBG level in DM only group was significantly higher compared with non-DM group. However, in $\mathrm{DM}+$ metformin group treated with $100 \mathrm{mg} / \mathrm{kg} /$ day, FBG was significantly lower compared with DM group (Table 1).

\subsection{Plasma Antioxidant Enzyme Levels}

Plasma CAT activity in DM group was significantly lower compared with the non-DM group. However, plasma CAT activity in DM+metformin group was significantly higher in comparison with the DM (positive control) group. Plasma GPx activity in DM and $\mathrm{DM}+$ metformin groups was significantly lower compared with the non-DM group. However, no significant difference was found for plasma SOD activity among all groups (Table 2 ).

\subsection{Plasma Oxidative Stress Markers}

Plasma MDA and PCO were significantly higher in DM group compared with non-DM group. However, plasma MDA and PCO in DM+metformin group were significantly lower compared with DM group but no significant difference with non-DM group (Table 3 ). Plasma TAC was significantly lower in DM group

Table 1: Fasting Blood Glucose Levels for all Experimental Groups

\begin{tabular}{|c|c|c|}
\hline Groups & $\begin{array}{c}\text { Initial FBG } \\
\text { (mg/dl) }\end{array}$ & $\begin{array}{c}\text { Final FBG } \\
\text { (mg/dl) }\end{array}$ \\
\hline \hline non-DM & $90.55(1.27)$ & $90.00(1.29)$ \\
\hline DM & $424.29(31.40)^{\mathrm{a}}$ & $547.57(61.18)^{\mathrm{a}}$ \\
\hline DM+metformin & $467.57(50.52)^{\mathrm{a}}$ & $306.00(67.49)^{\mathrm{a}, \mathrm{b}}$ \\
\hline
\end{tabular}

Data are mean (SD), n=7/group, DM: diabetes mellitus, FBG: fasting blood glucose, ${ }^{a} p<0.05$ compared with non-DM group; ${ }^{b} p<0.05$ compared with DM group (ANOVA followed by Tukey-Kramer post-hoc test).

Table 2: Plasma Antioxidant Enzymes for all the Groups

\begin{tabular}{|c|c|c|c|}
\hline Groups & $\begin{array}{c}\text { CAT } \\
\text { (U/mg protein) }\end{array}$ & $\begin{array}{c}\text { SOD } \\
\text { (U/ mg protein) }\end{array}$ & $\begin{array}{c}\text { GPx } \\
\text { (U/ mg protein) }\end{array}$ \\
\hline \hline non-DM & $4.414(0.875)$ & $2.554(4.187)$ & $241.802(157.57)$ \\
\hline DM & $0.090(0.087)^{\mathrm{a}}$ & $0.656(1.464)$ & $79.542(35.04)^{\mathrm{a}}$ \\
\hline DM+metformin & $1.158(0.538)^{\mathrm{a}, \mathrm{b}}$ & $0.681(0.202)$ & $102.347(65.26)^{\mathrm{a}}$ \\
\hline
\end{tabular}

Data are mean (SD), n=7/group, DM: diabetes mellitus, CAT: catalase, SOD: superoxide dismutase, GPx: glutathione peroxidase, ${ }^{a} p<0.05$ compared with non-DM group; ${ }^{b} p<0.05$ compared with DM group (ANOVA followed by Tukey-Kramer post-hoc test). 
Table 3: Plasma Oxidative Stress Markers for all the Groups

\begin{tabular}{|c|c|c|c|}
\hline Groups & $\begin{array}{c}\text { MDA } \\
\text { (nmol/ mg protein) }\end{array}$ & $\begin{array}{c}\text { PCo } \\
\text { (nmol/ mg protein) }\end{array}$ & $\begin{array}{c}\text { TAC } \\
\text { (nmol/ mg protein) }\end{array}$ \\
\hline \hline non-DM & $0.729(0.10)$ & $1.184(0.274)$ & $0.706(0.142)$ \\
\hline DM & $2.526(1.475)^{\mathrm{a}}$ & $3.663(1.076)^{\mathrm{a}}$ & $0.360(0.094)^{\mathrm{a}}$ \\
\hline DM+metformin & $1.040(0.184)^{\mathrm{b}}$ & $1.544(0.488)^{\mathrm{b}}$ & $0.479(0.096)^{\mathrm{b}}$ \\
\hline
\end{tabular}

Data are mean (SD), $n=7 /$ group, $D M$ : diabetes mellitus, MDA: malonyldehyde, PCO: protein carbonyls, TAC: total antioxidant capacity, ${ }^{a} p<0.05$ compared with nonDM group; ${ }^{b} p<0.05$ compared with DM group (ANOVA followed by Tukey-Kramer post-hoc test).

compared with non-DM group. The plasma TAC of $\mathrm{DM}+$ metformin group was significantly higher compared with DM group. However, there was no significant difference in the plasma MDA in $\mathrm{DM}+$ metformin group compared with non-DM group (Table 3).

\subsection{Plasma Insulin Levels}

The plasma insulin level was significantly lower in DM group compared with non-DM group. However, in $\mathrm{DM}+$ metformin group treated with $100 \mathrm{mg} / \mathrm{kg} / \mathrm{day}$, plasma insulin was significantly higher than DM group and significantly lower than non-DM group (Figure 1).

\section{DISCUSSION}

The lower FBG level in DM+metformin group is in line with previous report on metformin action in comparison with other oral antihyperglycemic drugs glibenclamide and repaglinide although plasma insulin level was not concomitantly measured [9]. This antihyperglycaemic action may be as a result of metformin ability to reduce blood glucose to a good glycaemic control without causing hypoglycaemia due to its mechanism of actions such as inhibits hepatic gluconeogenesis, decreases intestinal glucose absorption and increases peripheral glucose utilization [4]. It has been reported that metformin, via an adenosine monophosphate-activated protein kinasedependent mechanism, inhibits or suppresses glucose production and gluconeogenic gene expression in primary hepatocytes and in the liver of mice [19].

In this model of DM, treatment with metformin alone at a dose of $100 \mathrm{mg} / \mathrm{kg} /$ day for 4 weeks revealed remarkable improvement in the activity of antioxidant enzyme CAT. The improved CAT activity may explain the increased TAC found in the present study. The finding on improved CAT activity is in line with previous report on metformin at the dose of $25 \mathrm{mg} / \mathrm{kg}$ per day for 2 weeks. However, no improvement was seen for the activities of SOD and GPx following metformin treatment in the present study although previous study shows an improvement in SOD activity [9]. These contrary findings may be due to the different in the dose and duration of metformin used in the studies.

Reactive oxygen species are suggested to be among the important factors that alter metabolism and beta cells function [18]. Both streptozotocin and hyperglycaemia increase free radicals formations which

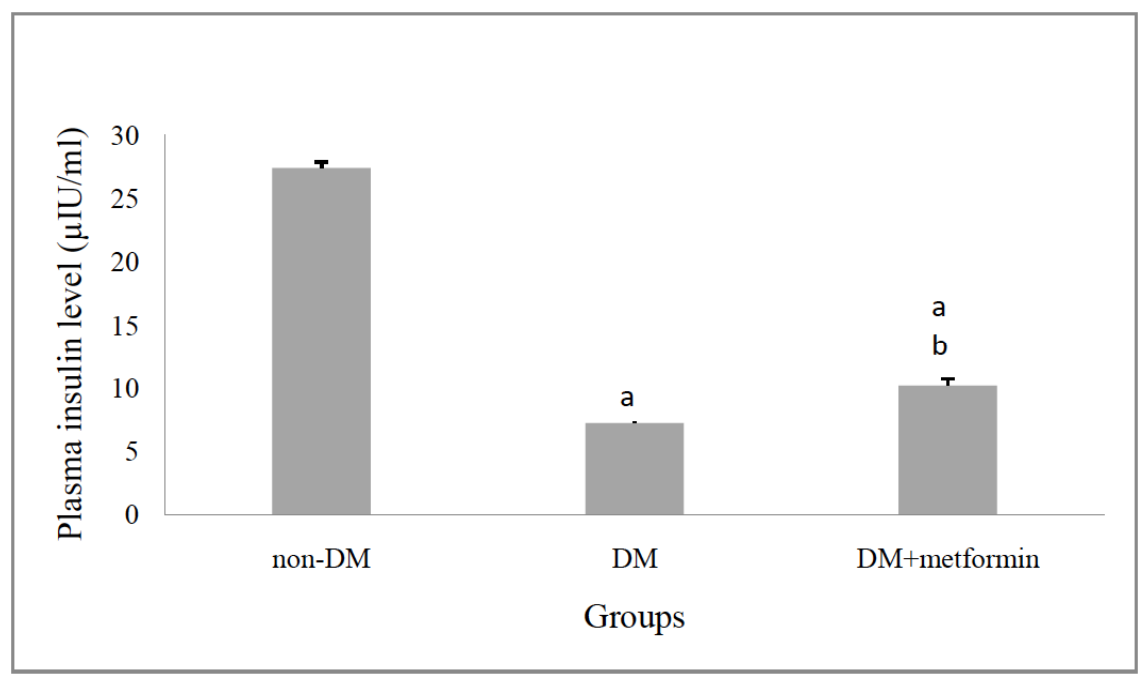

Figure 1: Plasma insulin levels in all experimental groups. Data are mean (SD), $n=7 / g r o u p$, DM: diabetes mellitus, ${ }^{a} p<0.05$ compared with non-DM group; ${ }^{b} p<0.05$ compared with DM group (ANOVA followed by Tukey-Kramer post-hoc test). 
can compromise antioxidant enzyme activities [19]. This may lead to the imbalance between the levels of oxidant and antioxidant enzyme activity as seen in the present study. In the present study, plasma MDA and PCO were significantly higher while TAC and CAT were significantly lower in DM group compared with non-DM group may suggest an increase in oxidative stress status in DM group. On the other hand, the plasma levels of MDA and PCO were significantly lower while CAT was significantly higher in DM+metformin group compared with DM group showing the indirect antioxidant effect of metformin possibly by its antihyperglycaemic effect. The decreased MDA level is in line with previous study using metformin at the doses of 25 [9] and $50 \mathrm{mg} / \mathrm{kg}$ per day [8]. Similarly, recent study has shown that metformin at a dose of $500 \mathrm{mg} / \mathrm{kg}$ per day for 7 days significantly reduces oxidative stress and prevents lipid peroxidation in gastrocnemius muscle of diabetic rats [20]. This is further supported by previous study that any substance with antihyperglycaemic effect potential may have indirect effect on oxidative stress by reducing the formation of free radicals from the auto-oxidation of glucose which in turn may protect the tissue from damage [21].

The significant decreased level of plasma insulin in DM group compared with non-DM and significantly higher plasma insulin in DM+metformin group compared with DM group are in accordance with previous study on metformin (50 $\mathrm{mg} / \mathrm{kg}$ per day for 2 weeks) in fructose fed-diabetic animal model [8]. It is also found that metformin lowered fasting blood glucose and improved insulin action in a pregnant woman with obesity [22]. Furthermore, the ability of metformin to ameliorate oxidative stress-induced damage associated with streptozotocin-induced diabetes could be secondary to its antihyperglycaemic effect and improve insulin action in both overweight patient and high fructose-fed rats [23]. Therefore, it is possible to suggest that the significant increase in plasma insulin level found in the present study may be due to antihyperglycaemic effect of metformin which can ameliorate oxidative stress and subsequently may improve the pancreatic beta cell function or may give a regenerative effect on the pancreatic beta cells that may potentiate the production or secretion of insulin by the beta cells which needs further studies. Moreover, the reduced oxidative stress following metformin treatment may also possibly enhance cellular response to insulin which in turn further contributes to its antihyperglycaemic effect.

\section{CONCLUSION}

In conclusion, this study suggests that metformin at the dose of $100 \mathrm{mg} / \mathrm{kg} / \mathrm{day}$ for 4 weeks reduces oxidative stress status as well as improves plasma insulin level in streptozotocin-induced diabetic model possibly through its antihyperglycaemic effect. Nevertheless, further studies are suggested to further evaluate the possible beneficial effects of metformin in protecting or reducing end organ damage.

\section{ACKNOWLEDGMENT}

The authors would like to thank Universiti Sains Malaysia for the financial support [USM Research University Grant (1001/PPSP/813072)].

\section{REFERENCES}

[1] American Diabetes Association (ADA, 2014). Classification and Diagnosis of Diabetes. Diabetes Care 2014; 38: S8-S16. http://www.diabetes.org/diabetescare

[2] Geneto M, Umeta M, Kebede T, Azazh A, Nagphaul R, Mohammed SF. Acomparative study on serum level concentration of micrnutrients like zinc, copper and chromium status in type 2 diabetic patients in diabetes and endocrnology unit, Tikur Anbessa specialized Hospital, Ethiopia. J Pharm Nutr Sci 2015; 5: 95-102. http://dx.doi.org/10.6000/1927-5951.2015.05.02.1

[3] Boyle J, Mckey G, Fisher M. Drugs for diabetes: Part 1 metformin. Braz J Cardiol 2010; 17: 231-4.

[4] Hur KY, Lee MS. New mechanisms of metformin action: Focusing on mitochondria and the gut. J Diabetes Investig 2015; 6: 600-9.

http://dx.doi.org/10.1111/jdi.12328

[5] Scheen AJ. Clinical pharmacokinetics of metformin. Clin Pharmacokinet 1996; 30: 359-71. http://dx.doi.org/10.2165/00003088-199630050-00003

[6] Gordon EE, Reinking BE, $\mathrm{Hu} \mathrm{S}$, et al. Maternal Hyperglycemia directly and rapidly induces cardiac septal overgrowth in Foetal rats. J Diabetes Res 2015; 3: 1-11. http://dx.doi.org/10.1155/2015/479565

[7] Lei XG, Vatamaniuk MZ. Two tales of antioxidant enzymes on beta cells and diabetes. Antioxid Redox Signal 2011; 14(3): 489-503.

http://dx.doi.org/10.1089/ars.2010.3416

[8] Anurag P, Anuradha CV. Metformin improves lipid metabolism and attenuates lipid peroxidation in higher fructose-fed rats. J Diab Obes Met 2002; 4: 36-42. http://dx.doi.org/10.1046/j.1463-1326.2002.00178.x

[9] Obi BC, Okoye TC, Okpashi VE, Igwe CN, Alumanah EO. Comparative study of the antioxidant effects of metformin, glibenclamide, and repaglinide in alloxan-induced diabetic rats. J Diab Res 2016; 1: 5-10. http://dx.doi.org/10.1155/2016/1635361

[10] Umar ZU, Abu Bakar AB, Mohamed M. A review on experimental methods of diabetic research: Advantages and limitations. Annu Res Rev Biol 2015; 7: 100-8. http://dx.doi.org/10.9734/ARRB/2015/17404

[11] Trinder P. Determination of blood glucose using an oxidaseperoxidase system with a non-carcinogenichromogen. J Clin Pathol 1969; 22: 158-61. http://dx.doi.org/10.1136/jcp.22.2.158

[12] Janknegt PJ. A comparison of quantitative and qualitative superoxide dismutase assays for application to low 
temperature microalgae. J Photochem Photobiol B 2007; 87: 218-26.

http://dx.doi.org/10.1016/j.jphotobiol.2007.04.002

[13] Zhu T. Effects of the iron-chelating agent deferoxamine on triethylene glycol dimethacrylate, 2-hydroxylethyl methacrylate, hydrogen peroxide-induced cytotoxicity. J Biomed Mater Res B Appl Biomater 2012; 100(1): 197-205. http://dx.doi.org/10.1002/jbm.b.31939-2012-197-205

[14] Pascual P, Martinez-Lara E, Bárcena JA, López-Barea J, Toribio F. Direct assay of glutathione peroxidase activity using high-performance capillary electrophoresis. J Chromatogr 1992; 581: 49-56. http://dx.doi.org/10.1016/0378-4347(92)80446-W

[15] Apak R, Guclu K, Ozyurek M, Karademir SE. Novel total antioxidant capacity index for dietary polyphenols and vitamins $C$ and $E$, using their cupric ion reducing capability in the presence of neucuproine: CUPRAC method. J Agric Food Chem 2004; 52: 7970-7981. http://dx.doi.org/10.1021/jf048741x-2004-7970-81

[16] Janero DR. Malondialdehyde and thiobarbituric acidreactivity as diagnostic indices of lipid peroxidation and peroxidative tissue injure. Free Rad Bio Med 1990; 9: 51540.

http://dx.doi.org/10.1016/0891-5849(90)90131-2

[17] Zusterzeel PIM, Mulder TP, Peters WHM. Plasm protein carbonyls nonpregnant healthy pregnant and preeclamptic women. Free Radic Res 2000; 33: 471-76. http://dx.doi.org/10.1080/10715760000301011

[18] Sharifuzzaman SM, Austin B. Kocuria SM1 controls vibriosis in rainbow trout (Oncorhynchus mykiss, Walbaum). J Appl Microbiol 2009; 108: 2162-70. http://dx.doi.org/10.1111/j.1365-2672.2009.04618.x
[19] Cao J, Meng S, Chang E, et al. Low concentrations of metformin suppress glucose production in hepatocytes through AMP-activated protein kinase (AMPK). J Biol Chem 2014; 289: 20435-46.

http://dx.doi.org/10.1074/jbc.M114.567271

[20] Bindokas VP, Kuznetsov A, Sreenan S, Polonsky KS, Roe MW, Philipson LH. Visualising superoxide production in normal and diabetic rats islets of Langerhans. J Biol Chem 2003; 278: 9796-801. http://dx.doi.org/10.1074/jbc.M206913200

[21] Del Rio D, Stewart AJ, Pellegrini N. A review of recent studies on malondialdehyde as toxic molecule and biological marker of oxidative stress. J Nutr Met Cardio Dis 2005; 15 : 316-28. http://dx.doi.org/10.1016/i.numecd.2005.05.003

[22] Vilela DD, Peixoto LG, Teixeira RR, et al. The role of metformin in controlling oxidative stress in muscle of diabetic rats. Oxid Med Cel Long 2016; 2016: 1-9. http://dx.doi.org/10.1155/2016/6978625

[23] Kumitoshi U, Katsuya D, Boldbaata D, et al. Lack of TRPM2 impaired insulin secretion and glucose metabolism in mice. J Diabetes 2011; 60: 119-26. http://dx.doi.org/10.2337/db10-0276

[24] Chiswick C, Reynolds RM, Denison F, et al. Effect of metformin on maternal and fetal outcomes in obese pregnant women (EMPOWaR): a randomised, double-blind, placebocontrolled trial. Lancet Diabetes Endocrinol 2015; 3: 778-86. http://dx.doi.org/10.1016/S2213-8587(15)00219-3

[25] Khan AS, Mcl oughney CR, Ahmed AB. The effect of metform on blood glucose control in overweight patient with type 1 diabetes. J Diabet Med 2006; 23: 1079-84 http://dx.doi.org/10.1111/j.1464-5491.2006.01966.x

Received on 27-10-2016

Accepted on 08-11-2016

Published on 28-11-2016

\section{DOI: http://dx.doi.org/10.6000/1927-5951.2016.06.04.1}

(c) 2016 Usman et al.; Licensee Lifescience Global.

This is an open access article licensed under the terms of the Creative Commons Attribution Non-Commercial License (http://creativecommons.org/licenses/by-nc/3.0/) which permits unrestricted, non-commercial use, distribution and reproduction in any medium, provided the work is properly cited. 